\title{
A Case of Severe Acute Exacerbation of Bronchial Asthma Treated with Low Minute Ventilation
}

\author{
- A Case Report-
}

Young Joo Han, M.D., Dong In Suh, M.D., Young Seung Lee, M.D. and June Dong Park, M.D.

Department of Pediatrics, Seoul National University College of Medicine, Seoul, Korea

We report a case of severe status asthmaticus in a 3-year-old boy who required mechanical ventilatory support. He initially presented with rapidly progressing respiratory distress and spontaneous air leaks. Although he was intubated and received mechanical ventilation, dynamic hyperinflation and air leaks were aggravated. We applied the volume control mode, providing sufficient tidal volume $(10 \mathrm{ml} / \mathrm{kg})$, a reduced respiratory rate $(25 / \mathrm{minute})$, and a prolonged expiratory time (1.8 seconds) to overcome dynamic hyperinflation. After allowing full expiration of trapped air, his over-expanded lung volumes were decreased and the air leaks resolved. He made a complete recovery without sequelae. Dynamic hyperinflation in asthmatic patients occurs from incomplete exhalation throughout narrowed airways. Controlled hypoventilation or permissive hypercapnia is an important lung-protective ventilator strategy and is beneficial in reducing dynamic hyperinflation. We suggest a controlled hypoventilation strategy with a prolonged expiratory time for patients in severe status asthmaticus with dynamic hyperinflation.

Key Words: air leak, controlled hypoventilation, intrinsic positive-pressure respiration, permissive hypercapnia, status asthmaticus.

Acute severe exacerbation of asthma is a life-threatening condition and may require mechanical ventilation. The morbidity and mortality from asthma is commonly associated with complications of air trapping caused by severe airway obstruction. These complications include air leaks, respiratory acidosis, and hypotension. ${ }^{1)}$

The goal of mechanical ventilation in patients with status asthmaticus is to provide sufficient gas exchange and to minimize complications associated with air trapping. Applied positive pressure to overcome severe airway obstruction can aggravate air trapping. ${ }^{2)}$ Therefore, it is difficult to make the optimal strategy for mechanical ventilation in children with status asthmaticus. ${ }^{1)}$

We report a case of successful use of mechanical ventilation in a child with severe status asthmaticus complicated by a spontaneous air leak.

Received on September 6, 2010, Accepted on October 18, 2010

Correspondence to: June Dong Park, Department of Pediatrics, Seoul National University College of Medicine, 28 Yeongeon-dong, Jongno-gu, Seoul 110-769, Korea

Tel: 82-2-2072-3359, Fax: 82-2-762-3359

E-mail: jdparkmd@snu.ac.kr

\section{CASE REPORT}

A 3-year-old, 15-kg boy with a history of atopic dermatitis and allergic rhinitis was admitted to the pediatric intensive care unit (PICU) of Seoul National University Children's Hospital (SNUCH) due to acute onset respiratory distress. A productive cough developed 5 days prior to admission. The cough gradually worsened, but was not severe. He had no diarrhea, vomiting, or rhinorrhea. A mild fever up to $37.5^{\circ} \mathrm{C}$ developed 2 days prior to admission. He visited a local clinic on that day and was diagnosed with acute pharyngitis. One day later, he complained of pain in his shoulders and chest. $\mathrm{He}$ had mild wheezing and had difficulty in breathing, which worsened within a few hours. He visited a local general hospital on that day. He had severe dyspnea and marked wheezing was heard on auscultation. A plain chest radiograph demonstrated a pneumomediastinum and subcutaneous emphysema.

He was intubated and transferred to another university hospital immediately. The arterial blood gas analysis (ABGA) was as follows: $\mathrm{pH}, 7.39 ; \mathrm{pCO}_{2}, 38.3 \mathrm{mmHg} ; \mathrm{pO}_{2}, 166 \mathrm{mmHg}$; and $\mathrm{HCO}_{3}{ }^{-}, 22.8 \mathrm{mM}$. A chest tube was inserted into the 
right side of his thorax since the repeated chest radiography showed a right-sided pneumothorax (Fig. 1). Aminophylline intravenously and epinephrine subcutaneously were administered. Dopamine and dobutamine were administered because hypotension had developed. The computed tomography (CT) of the chest demonstrated subcutaneous emphysema in both axillae and the left anterior chest wall, a pneumomediastinum, a right-sided hydropneumothorax, and a collapsed right upper and right middle lobe (Fig. 2). His respiration was assisted by manual bagging on $15 \mathrm{~L} /$ minute of oxygen since the oxygen

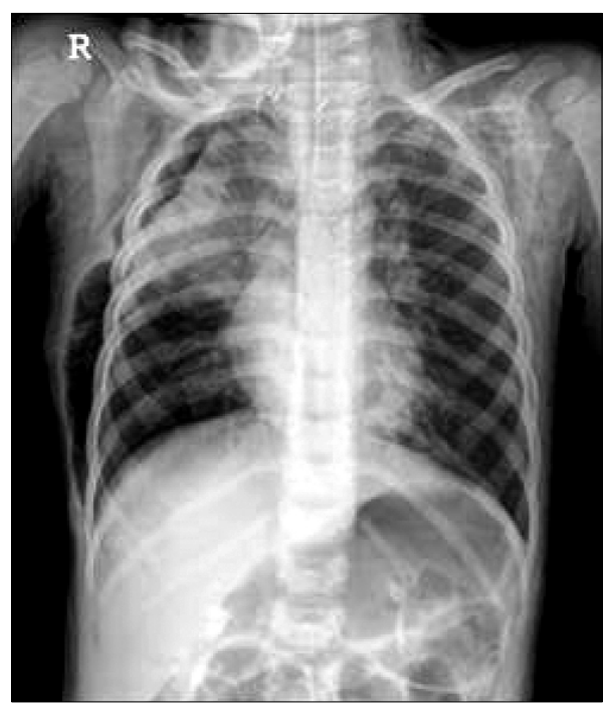

Fig. 1. A chest $x$-ray showing right-sided pneumothorax, collapsed right upper lobe and right middle lobe, pneumomediastinum, and subcutaneous emphysema.

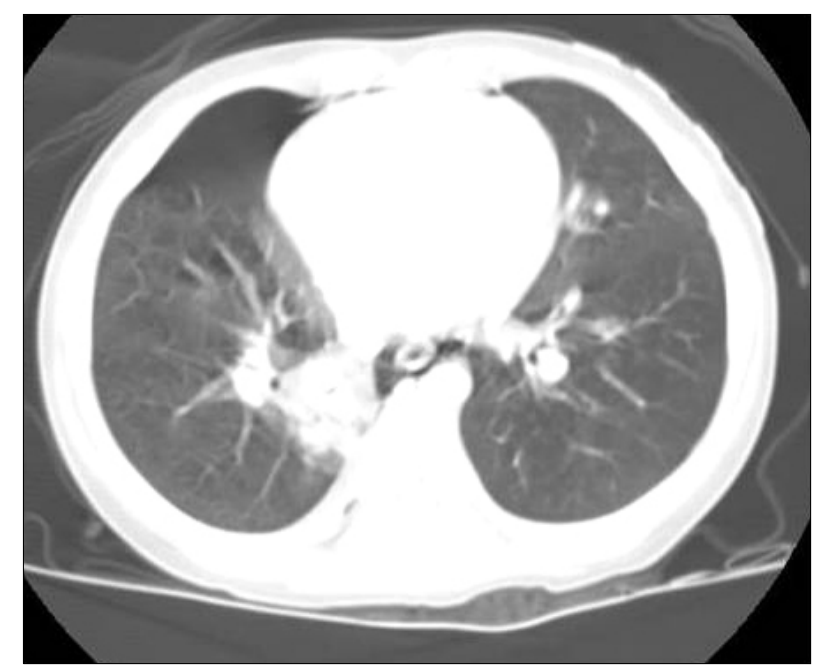

Fig. 2. A computed tomography showing pneumomediastinum, right-sided pneumothorax, and collapsed right middle lobe. saturation did not rise above $85 \%$ during mechanical ventilation with an $\mathrm{FiO}_{2}$ of 1.0. Therefore, he was transferred to the PICU of SNUCH the following day. The ABGA obtained before transfer revealed the following: $\mathrm{pH}, 7.356 ; \mathrm{pCO}_{2}, 39$ $\mathrm{mmHg}$; $\mathrm{pO}_{2}, 64 \mathrm{mmHg}$; and $\mathrm{HCO}_{3}{ }^{-}, 21.3 \mathrm{mM}$.

On admission to the PICU of SNUCH, his respiration was assisted by manual bagging. He had an oxygen saturation of $80-90 \%$ on $15 \mathrm{~L} /$ minute of oxygen. His blood pressure was $109 / 66 \mathrm{mmHg}$ and the pulse rate was 180 beats/minute. He had a temperature of $37.8^{\circ} \mathrm{C}$. His chest wall rarely expanded during inspiration. The breath sounds were reduced and severe wheezing was heard on auscultation in inspiratory and expiratory phases. The subcutaneous emphysema was observed on his face, neck, chest, abdomen, and both thighs. An ABGA revealed the following: $\mathrm{pH}, 6.9 ; \mathrm{pCO}_{2}, 115 \mathrm{mmHg}$; and $\mathrm{pO}_{2}, 89$ mmHg. A plain radiograph of the chest and abdomen demonstrated aggravation of the bilateral pneumothorax and subcutaneous emphysema (Fig. 3). A complete blood count revealed the following: hemoglobin, $13.4 \mathrm{~g} / \mathrm{dl}$; white blood cell count, $37,600 / \mu 1$; and platelet count, $410,000 / \mu 1$. The white blood cell differential count was as follows: neutrophils, $84.9 \%$; lymphocytes, $8.3 \%$; monocytes, $4.1 \%$; and eosinophils, $1 \%$. The serum chemistry was as follows: total calcium, $9.2 \mathrm{mg} / \mathrm{dl}$; phosphorus, $7.5 \mathrm{mg} / \mathrm{dl}$; blood urea nitrogen, $22 \mathrm{mg} / \mathrm{dl}$; creatinine, $0.8 \mathrm{mg} / \mathrm{dl}$; total bilirubin, $0.9 \mathrm{mg} / \mathrm{dl}$; aspartate aminotransferase, $161 \mathrm{IU} / \mathrm{L}$; alanine aminotransferase, $44 \mathrm{IU} / \mathrm{L}$; sodium, $140 \mathrm{mM}$; potassium, $5 \mathrm{mM}$; chloride, $108 \mathrm{mM}$; creatinine phosphokinase, $7,049 \mathrm{mg} / \mathrm{dl}$; lactate dehydrogenase, 698

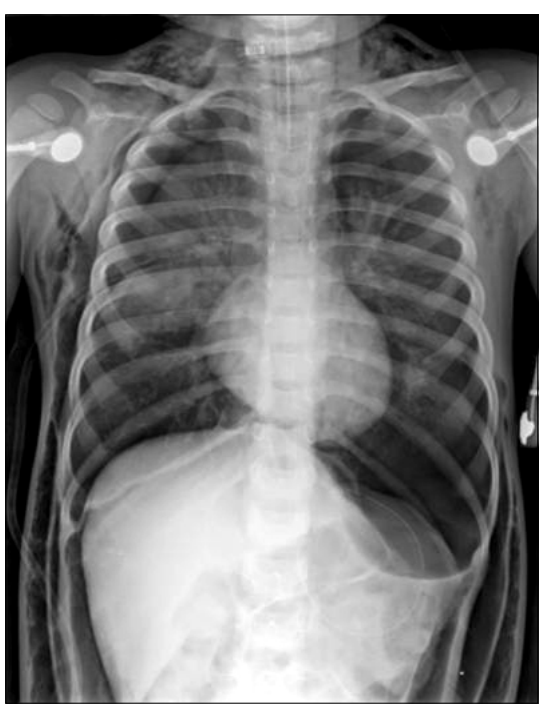

Fig. 3. A chest $x$-ray showing bilateral pneumothorax, aggravated pneumomediastinum, and subcutaneous emphysema. 
$\mathrm{mg} / \mathrm{dl}$; and C-reactive protein, $14.32 \mathrm{mg} / \mathrm{dl}$. The urinalysis revealed that his urine was concentrated.

The initial ventilator settings on a Servo 300 ventilator (Siemens, Munich, Germany) were the pressure-regulated volume control mode at a rate of 35/minute, a tidal volume of $110 \mathrm{ml}(7.3 \mathrm{ml} / \mathrm{kg})$, an $\mathrm{FiO}_{2}$ of 1.0 , and positive end-ex-
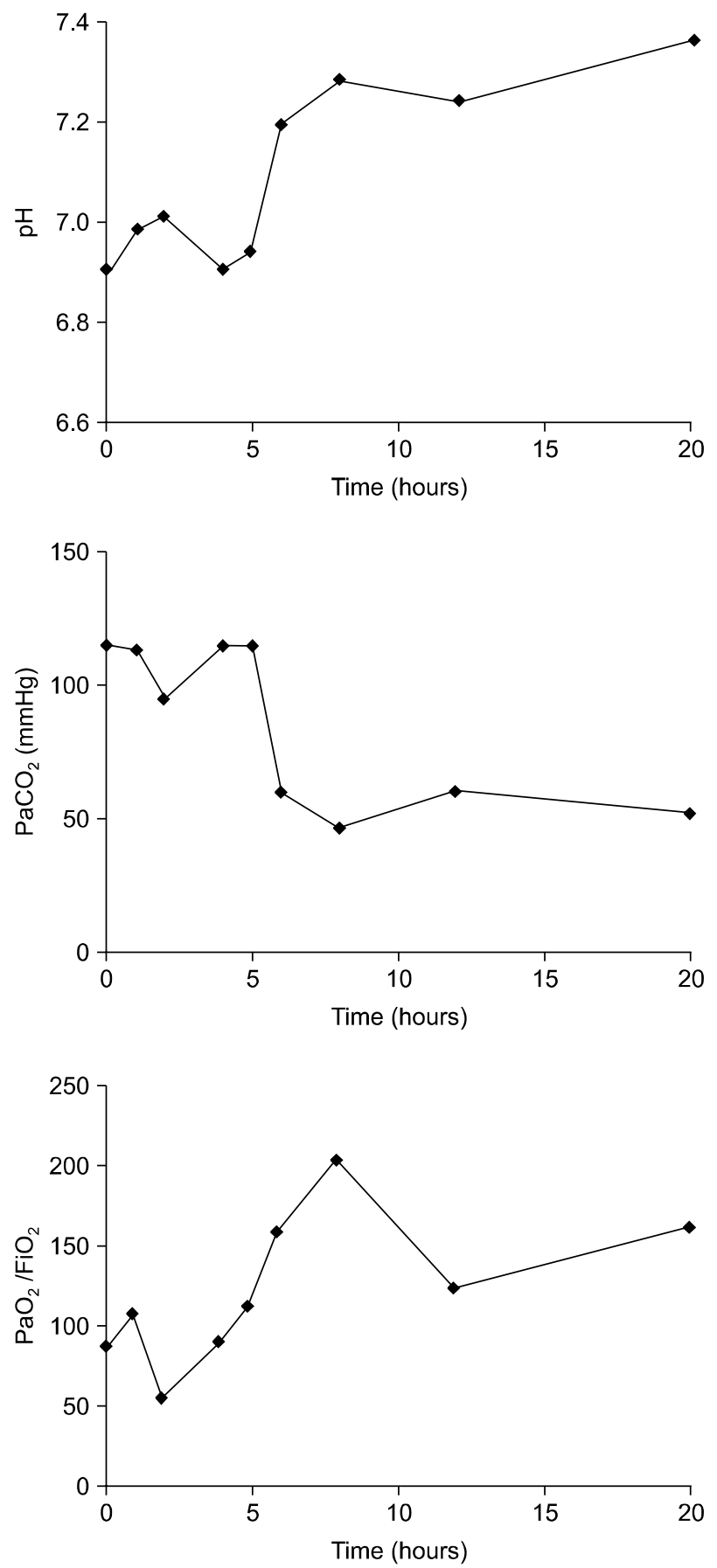

piratory pressure (PEEP) of $15 \mathrm{cmH}_{2} \mathrm{O}$. The measured peak in spiratory pressures were $80-100 \mathrm{cmH}_{2} \mathrm{O}$. Thoracenteses with large bore needles were performed on the right and left sides and $40 \mathrm{ml}$ of air was aspirated. A chest tube was inserted into the left side of his thorax. Hypotension developed and the dosage of inotropics was increased.
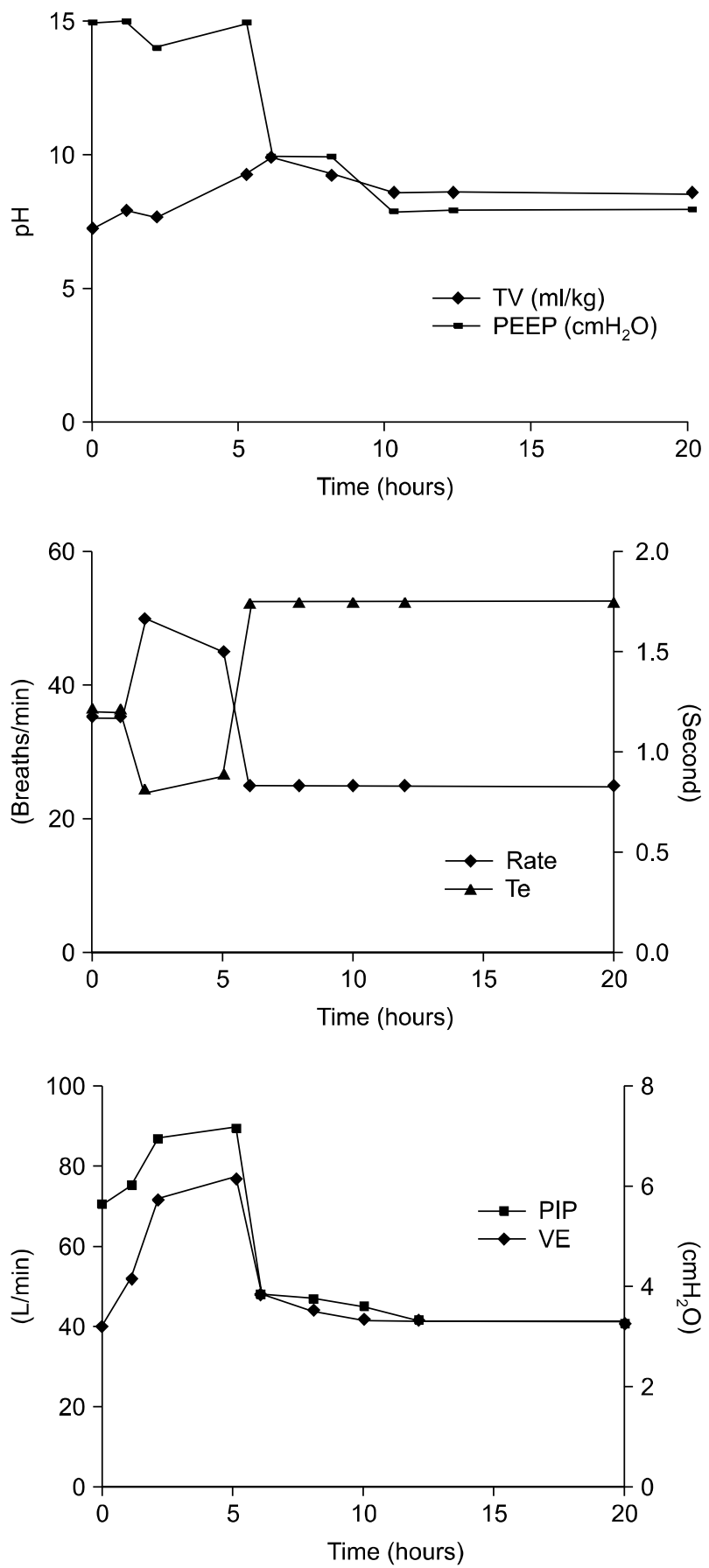

Fig. 4. Arterial blood gas analysis and ventilator indices during the initial 20 hours of admission. Te: expiratory time; TV: tidal volume; PEEP: positive end-expiratory pressure; PIP: peak inspiratory pressure; VE: minute ventilation. 
Although he had never been diagnosed with asthma before, status asthmaticus was suspected clinically. Epinephrine $(10 \mu \mathrm{g} /$ $\mathrm{kg} /$ dose) was administered subcutaneously twice again at 30-minute intervals with intravenous methylpredinisolone (2 $\mathrm{mg} / \mathrm{kg} /$ day) and cefotaxime. Nebulized salbutamol, micronized budesonide, and ipratropium bromide were administered via the endotracheal tube. The respiratory rate was increased to 50/minute. However, repeat ABGAs showed persistent respiratory acidosis with blood $\mathrm{pH}$ of $6.9-7.0$ and $\mathrm{pCO}_{2}$ of $95-115$ $\mathrm{mmHg}$ for 6 hours. Repeat chest radiographs demonstrated a reduction of the bilateral pneumothorax and persistent air trapping.

He was sedated with midazolam and fentanyl and paralyzed with vecuronium. The mode of ventilation was changed to the volume assist/control mode. The tidal volume was increased to $150 \mathrm{ml}(10 \mathrm{ml} / \mathrm{kg})$ and the respiratory rate and PEEP were reduced to $25 /$ minute and $10 \mathrm{cmH}_{2} \mathrm{O}$, respectively, to exhale trapped air and minimize further air trapping. This modification of ventilator settings reduced the set minute volume from 6.2 to $3.8 \mathrm{~L} /$ minute and prolonged the expiratory time from 0.9 to 1.8 seconds. Then, the measured peak inspiratory pressures decreased to approximately $40 \mathrm{cmH}_{2} \mathrm{O}$ and the chest radiographs demonstrated decreased lung volumes. A repeat ABGA done 15 minutes later showed an improved $\mathrm{pH}$ (7.19) and a diminished $\mathrm{pCO}_{2}(60 \mathrm{mmHg})$. The ventilator settings were maintained during that day and his airway pressures and ABGAs continued to improve (Fig. 4). Serial chest radiographs demonstrated improvement in emphysema and air leaks. The serum creatinine phosphokinase levels and liver enzyme levels improved later.

Oseltamivir was started on hospital day 3 because influenza A virus was detected in transtracheal aspirates using a polymerase chain reaction and immunofluorescence assays.

The allergy tests were done on hospital day 3. The blood eosinophil count was $40 / \mu 1$ and the serum ECP level was $12.2 \mathrm{ng} / \mathrm{ml}$. A radioallergosorbent test revealed class 3 to egg white and class 2 to milk, buckwheat, peanuts, and soya beans. Multiple allergen simultaneous tests revealed class $2-3$ to most outdoor allergens, such as sycamore trees, Bermuda grass, and short ragweed; it also revealed class 3 to egg white. The serum total $\mathrm{IgE}$ level was $1,760 \mathrm{U} / \mathrm{ml}$ initially and decreased to $1,140 \mathrm{U} / \mathrm{ml}$ on hospital day 9 and $304 \mathrm{U} / \mathrm{ml} 6$ weeks later.

He was extubated on hospital day 7. The chest tubes were removed and he was moved to the general ward on hospital day 8. He made a complete recovery and was discharged without complication on hospital day 11. Prednisolone was tapered off and he is currently treated with only inhaled micronized budesonide.

\section{DISCUSSION}

A case of acute serious exacerbation of asthma with a spontaneous air leak, which is a rare condition in children, ${ }^{3)}$ and severe respiratory acidosis unresponsive to initial treatment has been presented.

Status asthmaticus describes a serious asthmatic attack unresponsive to standard therapy. Patients with acute severe asthma exacerbation are at risk of air trapping and lung hyperinflation, which may lead to alveolar rupture and cardiovascular compromise. ${ }^{1,4-6)}$ Lung hyperinflation in severe asthma is related to airflow obstruction, increased ventilatory demands, and incomplete exhalation. When exhalation is interrupted by the next breath, air trapping develops. Consequently, the lung fails to return to its functional residual capacity (FRC) at the end of expiration and there becomes additional pressure, which is called intrinsic PEEP or auto-PEEP. ${ }^{7)}$ Although lung hyperinflation is an adaptive mechanism to expand small airways and reduce airway resistance, air leaks and hypotension may develop finally in the state of excessive lung hyperinflation. ${ }^{8)}$

The initial hospital management of acute asthmatic attack is important to prevent aggravation of dynamic hyperinflation. Intensive pharmacotherapy to decrease airway resistance should be started immediately. Administration of inhaled beta-receptor agonists as bronchodilators and systemic corticosteroids as anti-inflammatory agents is the first-line of therapy for most patients with severe asthma exacerbation. ${ }^{9)}$ In patients who are unresponsive to intermittent inhalation of beta-receptor agonists, continuous inhalation therapy is indicated. ${ }^{10)}$ The addition of inhaled anticholinergics is recommended as well. ${ }^{2)}$

Children with status asthmaticus who deteriorate may require mechanical ventilation. The decision to intubate an asthmatic child should be based mainly on clinical judgment. Positive pressure ventilation easily worsens air trapping and increases the risk of air leaks, which is related to adverse events in severe asthma. ${ }^{6}$ Controlled hypoventilation or permissive hypercapnia with reduced minute ventilation is known as the lung-protective strategy to minimize lung injuries associated with positive pressure ventilation. ${ }^{11-13)}$ Normalization of $\mathrm{PaCO}_{2}$ by high minute ventilation is usually not the first priority and may worsen dynamic hyperinflation. ${ }^{8,14)}$ Respiratory acidosis 
with an arterial $\mathrm{pH}>7.2$ or a $\mathrm{PaCO}_{2}<90 \mathrm{mmHg}$ is considered to be tolerable ${ }^{4,15)}$ without the risks of increased intracranial pressure ${ }^{16)}$ or cardiovascular instability. ${ }^{17)}$ Therefore, the controlled hypoventilation strategy with a goal of $\mathrm{P}_{\text {plat }}<30$ $\mathrm{cmH}_{2} \mathrm{O}$ using a relatively low tidal volume and maximal expiratory time by reducing respiratory frequency and increasing inspiratory flow is recommended to minimize dynamic hyperinflation in ventilated asthmatics. ${ }^{7)}$ Administration of sedatives or neuromuscular blockade is usually required to improve patient-ventilator synchrony.

Either the volume or pressure control mode of ventilation is available in severe asthma. The volume control mode can provide constant tidal volume in the condition of changing airway resistance. The pressure control mode provides constant pressure with variable decelerating inspiratory flow pattern and initial peak inspiratory flow, which leads to more turbulent flow in the condition of extremely high airway resistance. Turbulent flow makes the ventilation inefficient and results in the escalation of ventilator setting.

To overcome severe respiratory acidosis, we initially tried to provide adequate minute ventilation by setting high respiratory rate rather than large tidal volume which contributes to increasing peak inspiratory pressure and worsening air leaks. However, frequent respiration caused incomplete exhalation and consequently worsened hypercapnia, air rapping, and air leaks. ${ }^{18)}$ Nevertheless, we raised the ventilatory rate intending to improve hypercapnia by increasing minute ventilation, which was not helpful because of persistent air trapping. Finally, using volume assist/control mode, we reduced the ventilatory rate greatly to allow sufficient time for exhalation and succeeded to terminate the vicious cycle of severe dynamic hyperinflation. As the volume of lung decreased, the peak inspiratory pressure decreased and air leaks were improved eventually. This improvement shows that an inspiratory to expiratory time ratio (I : E ratio) and minute ventilation are important determinants of dynamic hyperventilation.

Volume of trapped air can be estimated by sum of tidal volume and exhaled volume during 20-60 seconds of apnea. ${ }^{19)}$ Intrinsic PEEP can be estimated by measuring pressure at airway opening during an end-expiratory hold method. ${ }^{20)}$ Monitoring of lung volumes using these maneuvers, which was not performed in our case, is important in the condition of chronic airflow obstruction.

We experienced a pediatric status asthmaticus patient complicated by extensive air leaks, who treated by volume-controlled mechanical ventilation using prolonged expiratory time without sequelae. Guarantee of complete exhalation and monitoring of lung volumes are essential in ventilation of asthmatic patients.

\section{REFERENCES}

1) Stather DR, Stewart TE: Clinical review: Mechanical ventilation in severe asthma. Crit Care 2005; 9: 581-7.

2) Expert panel report 3: guidelines for the diagnosis and management of asthma. Bethesda, Maryland: National Institutes of Health, National Asthma Education and Prevention Program; 2007 NIH Publication No08-4051 http://www.nhlbi.nih.gov/ guidelines/asthma/asthgdln.pdf.

3) Khalid MS, Ahmad N, Moin S, El-Faedy O, Gaffney P: Spontaneous pneumomediastinum: a rare complication of acute asthma. Ir J Med Sci 2008; 177: 393-6.

4) Papiris S, Kotanidou A, Malagari K, Roussos C: Clinical review: severe asthma. Crit Care 2002; 6: 30-44.

5) Werner HA: Status asthmaticus in children: a review. Chest 2001; 119: 1913-29.

6) Pinhu L, Whitehead T, Evans T, Griffiths M: Ventilator-associated lung injury. Lancet 2003; 361: 332-40.

7) Levy BD, Kitch B, Fanta $\mathrm{CH}$ : Medical and ventilatory management of status asthmaticus. Intensive Care Med 1998; 24 : 105-17.

8) Tuxen DV, Lane S: The effects of ventilatory pattern on hyperinflation, airway pressures, and circulation in mechanical ventilation of patients with severe air-flow obstruction. Am Rev Respir Dis 1987; 136: 872-9.

9) Chipps BE, Murphy KR: Assessment and treatment of acute asthma in children. J Pediatr 2005; 147: 288-94.

10) Camargo CA Jr, Spooner CH, Rowe BH: Continuous versus intermittent beta-agonists in the treatment of acute asthma. Cochrane Database Syst Rev 2003; CD001115.

11) Ventilation with lower tidal volumes as compared with traditional tidal volumes for acute lung injury and the acute respiratory distress syndrome. The Acute Respiratory Distress Syndrome Network. N Engl J Med 2000; 342: 1301-8.

12) Williams TJ, Tuxen DV, Scheinkestel CD, Czarny D, Bowes G: Risk factors for morbidity in mechanically ventilated patients with acute severe asthma. Am Rev Respir Dis 1992; 146: 607-15.

13) Laffey JG, O'Croinin D, McLoughlin P, Kavanagh BP: Permissive hypercapnia--role in protective lung ventilatory strategies. Intensive Care Med 2004; 30: 347-56.

14) Thorevska NY, Manthous CA: Determinants of dynamic hyperinflation in a bench model. Respir Care 2004; 49: 1326-34.

15) Goldstein B, Shannon DC, Todres ID: Supercarbia in children: clinical course and outcome. Crit Care Med 1990; 18: 166-8.

16) Brian JE Jr: Carbon dioxide and the cerebral circulation. Anesthesiology 1998; 88: 1365-86.

17) Orchard $\mathrm{CH}$, Kentish JC: Effects of changes of $\mathrm{pH}$ on the contractile function of cardiac muscle. Am J Physiol 1990; 258: C967-81. 
18) Vieillard-Baron A, Prin S, Augarde R, Desfonds P, Page B, Beauchet $A$, et al: Increasing respiratory rate to improve $\mathrm{CO} 2$ clearance during mechanical ventilation is not a panacea in acute respiratory failure. Crit Care Med 2002; 30: 1407-12.

19) Corbridge TC, Hall JB: The assessment and management of adults with status asthmaticus. Am J Respir Crit Care Med 1995; 151: 1296-316.

20) Pepe PE, Marini JJ: Occult positive end-expiratory pressure in mechanically ventilated patients with airflow obstruction: the auto-PEEP effect. Am Rev Respir Dis 1982; 126: 166-70. 